\title{
A powerful transgenic tool for fate mapping and functional analysis of newly generated neurons
}

\author{
Jingzhong Zhang ${ }^{1}$, Florian Giesert ${ }^{1}$, Karina Kloos ${ }^{1}$, Daniela M Vogt Weisenhorn ${ }^{1,2,5}$, Ludwig Aigner ${ }^{3}$, \\ Wolfgang Wurst ${ }^{1,2,4,5^{*}}$, Sebastien Couillard-Despres ${ }^{3^{*}}$
}

\begin{abstract}
Background: Lack of appropriate tools and techniques to study fate and functional integration of newly generated neurons has so far hindered understanding of neurogenesis' relevance under physiological and pathological conditions. Current analyses are either dependent on mitotic labeling, for example BrdU-incorporation or retroviral infection, or on the detection of transient immature neuronal markers. Here, we report a transgenic mouse model (DCX-CreERT2) for time-resolved fate analysis of newly generated neurons. This model is based on the expression of a tamoxifen-inducible Cre recombinase under the control of a doublecortin (DCX) promoter, which is specific for immature neuronal cells in the CNS.

Results: In the DCX-CreERT2 transgenic mice, expression of CreERT2 was restricted to DCX+ cells. In the CNS of transgenic embryos and adult DCX-CreERT2 mice, tamoxifen administration caused the transient translocation of CreERT2 to the nucleus, allowing for the recombination of loxP-flanked sequences. In our system, tamoxifen administration at E14.5 resulted in reporter gene activation throughout the developing CNS of transgenic embryos. In the adult CNS, neurogenic regions were the primary sites of tamoxifen-induced reporter gene activation. In addition, reporter expression could also be detected outside of neurogenic regions in cells physiologically expressing DCX (e.g. piriform cortex, corpus callosum, hypothalamus). Four weeks after recombination, the vast majority of reporter-expressing cells were found to co-express NeuN, revealing the neuronal fate of DCX+cells upon maturation.

Conclusions: This first validation demonstrates that our new DCX-CreERT2 transgenic mouse model constitutes a powerful tool to investigate neurogenesis, migration and their long-term fate of neuronal precursors. Moreover, it allows for a targeted activation or deletion of specific genes in neuronal precursors and will thereby contribute to unravel the molecular mechanisms controlling neurogenesis.
\end{abstract}

\section{Background}

Neurogenesis is a strictly controlled process generating and maintaining the complex CNS cytoarchitecture. In the adult brain, neurogenesis constitutes in addition a form of cellular neuronal plasticity by continuously generating new neurons from resident neural stem cells (NSCs). Neurogenesis progresses through several sequential events, including proliferation, neuronal

\footnotetext{
* Correspondence: wurst@helmholtz-muenchen.de; s.couillard-despres@pmu. ac.at

'Institute of Developmental Genetics, Helmholtz Zentrum Muenchen, German Research Center for Environmental Health $(\mathrm{GmbH})$, Ingolstaedter Landstrasse 1, D-85764 Neuherberg, Germany

${ }^{3}$ Institute of Molecular Regenerative Medicine, Paracelsus Medical University

Salzburg, Strubergasse 21, 5020 Salzburg, Austria

Full list of author information is available at the end of the article
}

lineage restriction of precursors, cell cycle exit, migration and integration into target area, differentiation, as well as morphological and functional maturation. At the end of this process, newly generated cells can be found as functionally integrated and active neurons [1-3].

Neuronal precursors and newly generated neurons can be identified by their expression of doublecortin (DCX) $[4,5]$. In the adult CNS, expression of DCX is mainly detected in the adult dentate gyrus of the hippocampus and in the subventricular zone/rostral migration stream/ olfactory bulb axis (SVZ/RMS/OB) [4,6-8]. Based on the close association between DCX expression and neurogenesis [5], we previously generated transgenic mice, to monitor neurogenesis in vitro and in vivo, in which reporter genes were driven by the DCX promoter [9-13].
C Biomed Central 
The potential of involving adult neurogenesis in therapeutic strategies to replace pathological neuronal losses urges for a better understanding of neurogenesis at the molecular and cellular levels. In addition, accumulating evidence indicates that abnormal neurogenesis might be involved in the pathogenesis of neuropsychiatric disorders [14-16]. Therefore, to understand and dissect the molecular mechanisms driving neurogenesis in vivo, various models have been developed over the last years. For example, transgenic models have been generated based on cell-type specific promoters such as nestin, GLAST, PLP (proteolipid protein), or DCX to investigate the biology of neural stem cells, radial glia, oligodendroglial precursors and neuronal precursors, respectively [11,17-21]. However, these reporter mice are not suitable for long-term studies such as fate tracing or studies on the long-term functional integration of the newly generated neurons. For example, in the SVZ/OB axis and in the dentate gyrus DCX is expressed in newly generated neurons only transiently (mostly less than 1 month in rodents' DG and OB) [4], and thus, the DCX reporter mice are not applicable for fate mapping studies. In the other groups of mice, the GLAST or nestin promoter-driven expression of Cre-recombinase takes place in cells that are still multipotent and as a consequence the fate of these cells is not exclusively neuronal. Therefore, the lack of suitable models to study specifically neuronal precursors' long-term fate still constitutes a major deficit.

To remedy this absence of suitable tool for neuronal precursor fate analysis, we generated transgenic mice bearing the tamoxifen-inducible CreERT2 recombinase gene under the control of the DCX promoter. In this report, we demonstrate that this new transgenic tool allows for time-resolved permanent labeling of newly generated neurons and long-term analysis of their fate. Moreover, it provides a platform to induce and eliminate expression of genes in a crucial time window of neuronal maturation and study the functional consequences of these manipulations.

\section{Methods}

\section{Plasmid Constructs}

A 2380-bp Sal I-Not I fragment of pCAG-CreERT2bpA-SS1 vector containing the CreERT2 cDNA was subcloned into the BamH I and Not I site of the phuDCX-3509-DsRed2 cassette [9], which contains the promoter region of human DCX, resulting in the phuDCX-3509-CreERT2 (Additional file 1). A 7.7-kb DCX-3'UTR (3'UTR) was amplified with RT-PCR, following the manufacturer's instructions (Invitrogen Kit; catalog No. 11904-018). PCR amplifications were performed with the sense primer 5'-ACTAGTAAGATGATAGGCTAAATCAAAGCC-3' and antisense primer 5'-
GCGGCCGCTTTTTTTTTTTTTTTTTTTATTGAAATCAAATTTTAT-3'. The Spe I and Not I sites were inserted in the $5^{\prime}$ terminal of primers respectively (the italic sequences with underlines). PCR products were cloned into a pCRII vector (TOPO TA Cloning Kit; Invitrogen; catalog No. K4600-01) to obtain the pCRIITOPO-3'UTR plasmid. A 7.7-kb Spe I-Not I fragment of pCRII-TOPO-3'UTR was subcloned into the Spe I and Not I site of the phuDCX-3509-CreERT2 cassette to get the phuDCX-3509-CreERT2-3'UTR targeting plasmid.

\section{Generation of the DCX-CreERT2 transgenic mice}

The targeting plasmid, phuDCX-3509-CreERT2-3'-UTR, was linearized by digestion with Sal I-Not I. The purified linearized DNA was microinjected into the pronuclei of fertilized oocytes of FVB inbred mice. Genotypes of the offspring were determined by PCR analysis and Southern Blot of tail DNA. An initial screen of the offspring was performed via PCR analysis with Cre sense primer 5'-TGCATTACCGGTCGATGCAAC-3' and the antisense primer 5'-GAAATCAGTGCGTTCGAACGCTAGA-3'. Cre-positive mice were further analyzed with Southern Blot (Additional file 1). A 1.27-kb Sal I-Hind III fragment of pCAG-CreERT2-bpA-SS1 vector was employed for preparing the probe with random primer (GE Healthcare Kit; catalog No. RPN 1633), the labeling probe was purified with MicroSpin S-300 HR (GE Healthcare Kit; catalog No. 27-5130-01) following the manufacturer's instructions. In case of positive insertion this probe detects a $7424 \mathrm{bp}$ fragment after digestion of the genomic DNA with Kpn I, or two fragments after digestion with EcoR $V$ (the size of one fragment is 8415 bp and the other at least is over $4103 \mathrm{bp}$ ). (All restriction enzymes are from Roche Applied Science).

\section{Transgenic Mice Treatments}

Animal experiments were carried out in accordance with the Council of European Communities Directive of the 24 November 1986 (86/609/EEC) and approved by the HelmholtzZentrum Munich Institutional Animal Care and Use Committee. To expand the DCXCreERT2 transgenic mouse line, DCX-CreERT2 transgenic mice were backcrossed with wildtype C57Bl/6J mice. DCX-CreERT2 transgenic mice were in addition mated with two reporter lines: CAG-CAT-EGFP mice [22] or ROSA26 ${ }^{\text {lacZ }}$ mice [23] to obtain DCX-CreERT2: ROSA26 ${ }^{\text {lacZ }}$ or DCX-CreERT2:CAG-CAT-EGFP double transgenic mice. Recombination activity in these lines induces expression of the corresponding reporter gene and was used for the various analyses described hereafter.

Tamoxifen (TAM, T-5648, Sigma-Aldrich) was dissolved in corn oil (C-8267, Sigma-Aldrich) at a stock 
concentration of $10 \mathrm{mg} / \mathrm{ml}$. To analyze the expression of CreERT2 or reporter genes in embryonic stages $20 \mu \mathrm{g}$ $\mathrm{TAM} / \mathrm{g}$ bodyweight was injected once intraperitoneally (i.p.) into pregnant mothers at different gestational stages. One day after the TAM injection, embryos were dissected for whole-mount X-Gal staining or immunostaining. To follow the fate of cells targeted at embryonic stages during adulthood, the same protocol of TAM injection was employed in pregnant females of 17.5 day gestational stage, and the offspring was sacrificed at 2 months of age. To identify whether the CreERT2 recombination can be activated with a single TAM injection in adult brain (8 to 10 week-old), one dose of $200 \mu \mathrm{g} \mathrm{TAM} / \mathrm{g}$ bodyweight was injected (i.p.) and mice were analyzed 1 day later. Finally, study of the expression patterns of CreERT2, reporter genes and cell-type specific markers in the adult brain was realized by injecting daily $100 \mu \mathrm{g}$ TAM/g bodyweight (i.p.) for 5 consecutive days. These mice were analyzed 2 days (D2), 8 days (D8), 15 days (D15), or 29 days (D29) after the last TAM injection. For all experiment control mice were included that were injected with vehicle only, i.e. corn oil.

Twenty-four hours prior to perfusion, mice were injected with $200 \mu \mathrm{g} / \mathrm{g}$ bodyweight BrdU (5-Bromo-2'deoxyuridine; B5002; Sigma-Aldrich) prepared in sterile PBS, pH7.4.

\section{Histology}

For whole-mount X-gal staining, embryos were fixed by immersion in $4 \%$ paraformaldehyde (PFA), $5 \mathrm{mM}$ EGTA, $10 \mathrm{mM} \mathrm{MgCl} 2$ in PBS solution for 30 minutes at room temperature (RT). They were then rinsed in $0.1 \mathrm{M}$ sodium phosphate buffer $\mathrm{pH} 7.4(\mathrm{~PB}), 2 \mathrm{mM} \mathrm{MgCl}$, $0.01 \%$ sodium deoxycholate, $0.02 \% \mathrm{NP}-40$, and incubated with X-gal staining buffer $(0.1 \% \mathrm{X}$-gal, $2 \mathrm{mM}$ $\mathrm{MgCl}_{2}, 0.01 \%$ sodium deoxycholate, $0.02 \% \mathrm{NP}-40$, $5 \mathrm{mM} \mathrm{K}_{3} \mathrm{Fe}(\mathrm{CN})_{6}, 5 \mathrm{mM} \mathrm{K}_{4} \mathrm{Fe}(\mathrm{CN})_{6}$ in $\left.\mathrm{PB}\right)$ for several hours in the dark at $37^{\circ} \mathrm{C}$ to visualize the beta-galactosidase ( $\beta$-gal) activity as a blue reaction product. Stained embryos were washed twice in PBS and post-fixed with $4 \%$ PFA in PBS overnight at $4^{\circ} \mathrm{C}$. X-gal staining of free floating sections was carried out as described above, with the modification that sections were post-fixed with $4 \%$ PFA in PBS only $1 \mathrm{~h}$ at RT, and then lightly counterstained with Eosin Y (0.1\%, E4382, Sigma-Aldrich).

Embryos for immunohistology were fixed by immersion in $4 \%$ paraformaldehyde (PFA) in $0.1 \mathrm{M}$ phosphate buffer $\mathrm{pH} 7.5$ for $2-8 \mathrm{hrs}$. Thereafter the whole embryo was embedded in paraffin, and sagittally sectioned $(8 \mu \mathrm{m})$ using a Microm HM $355 \mathrm{~s}$ Microtome (Leica).

Brains of adult mice were removed after transcardial perfusion with $4 \%$ PFA in $0.1 \mathrm{M}$ phosphate buffer $\mathrm{pH}$ 7.5. Brains were post-fixed for 2 hours in the same fixative. Thereafter, brains were immersed in 20\% sucrose at $4^{\circ} \mathrm{C}$ overnight and embedded in OCT compound. Brains were sectioned using a Leica cryostat into serial coronal or sagittal sections $(40 \mu \mathrm{m})$ for a systematic sampling of the entire brain.

\section{Immunostainings}

For immunofluorescence staining, free-floating sections were rinsed with $\mathrm{PBS}$ and blocked with $\mathrm{PBS}++(\mathrm{PBS}++$ : $5 \%$ fetal calf serum, $0.3 \%$ Triton X-100 in PBS) for $1 \mathrm{~h}$ at RT. However, in cases of staining involving the detection of BrdU, sections were pretreated in $2 \mathrm{~N} \mathrm{HCl}$ at $37^{\circ} \mathrm{C}$ for $30 \mathrm{~min}$, followed by a $10 \mathrm{~min}$ neutralization in $0.1 \mathrm{M}$ borate buffer and six washes in PBS prior to blocking. Then they were incubated in PBS++ containing primary antibody dilutions (see Table 1) for 24 hours at $4^{\circ} \mathrm{C}$, followed by three 10 min washes in PBS. Sections were then incubated with secondary antibody conjugated to cyanine 2 (cy2), cy3 or cy5 diluted in PBS++ for $2 \mathrm{~h}$ at RT (1:400, Jackson ImmunoResearch Lab). After three 10 min washes in PBS, sections were incubated with $5 \mathrm{mg} / \mathrm{ml}$ 4',6'-diamidino-2-phenylindole (DAPI) (SigmaAldrich, D9564) for $20 \mathrm{~min}$, followed by three $5 \mathrm{~min}$ washes in PBS. Finally, sections were mounted with Aqua poly/Mount (Polysciences, 18606).

\section{Statistics}

A minimum of 100 positive cells per region of interest in each animal and for each time point were counted to quantify the recombination events. Data are presented as mean $\pm \mathrm{SD}$.

\section{Results}

\section{Generation of transgenic Dcx-CreERT2 mice}

We previously demonstrated that a 3509-bp DCX genomic fragment could properly drive expression of reporter genes in neuronal precursors and immature neurons in vitro and in vivo $[9,10]$. Therefore, the CreERT2 encoding sequences were subcloned downstream of this DCX regulatory fragment (Additional file 1). Two male founders carrying the CreERT2 transgene were obtained after pronuclear injection. Both founders transmitted their transgene to the F1 generation and Southern blot analysis suggested that only 1 copy of the transgene was integrated into the host genome (Additional file 1).

Cre-recombinase activity was assessed on the F1 generation of both founder-derived lines following mating with Rosa $26^{\text {lacZ }}$ reporter mice bearing a lacZ expression cassette activated following recombination [23]. Two month-old DCX-CreERT2:Rosa26 $6^{\text {lacZ }}$ mice were perfused two weeks after a tamoxifen (TAM) or vehicle injection and stained for $\beta$-gal activity. Both DCX-CreERT2 transgenic lines exhibited the expected 
Table 1 Primary antibodies used for immunohistology

\begin{tabular}{|c|c|c|c|}
\hline Antigens & Antibodies & Dilutions & Companies \\
\hline $\mathrm{DCX}$ & goat anti-DCX & $1: 200$ & $\begin{array}{l}\text { Santa Cruz, } \\
\text { sc-8066 }\end{array}$ \\
\hline choline acetyltransferase (CHAT) & goat anti-CHAT & 1:100 & Millipore, Chemicon, AB144P \\
\hline Cre recombinase & rabbit anti-Cre & 1:500 & Abcam, ab24608 \\
\hline GFAP & rabbit anti-GFAP & $1: 1000$ & $\begin{array}{l}\text { DAKO, } \\
\text { Z0334 }\end{array}$ \\
\hline GAD65 & rabbit anti-GAD65 & 1:1000 & Millipore, Chemicon, AB5082 \\
\hline tyrosine hydroxylase $(\mathrm{TH})$ & rabbit anti-TH & 1:5000 & Pel-Freez, P40101 \\
\hline calretinin & rabbit anti-calretinin & $1: 2000$ & $\begin{array}{l}\text { Swant, } \\
7699 / 4\end{array}$ \\
\hline ionized calcium-binding adaptor molecule 1 (Iba1) & rabbit anti-lba1 & 1:500 & $\begin{array}{l}\text { Wako, } \\
\text { 019-19741 }\end{array}$ \\
\hline GFP & chicken anti-GFP & 1:1000 & $\begin{array}{l}\text { Aves, } \\
\text { GFP1020 }\end{array}$ \\
\hline beta-galactosidase & chicken anti-beta-galactosidase & 1:1000 & $\begin{array}{l}\text { Abcam, } \\
\text { ab9361 }\end{array}$ \\
\hline NeuN & mouse anti-NeuN & $1: 200$ & Millipore, Chemicon, MAB377 \\
\hline calbindin D-28K & mouse anti-calbindin-D-28K & $1: 2000$ & Sigma-Aldrich, C9848 \\
\hline 2', 3'-cyclic nucleotide 3'-phosphodiesterase (CNPase) & mouse anti-CNPase, & $1: 200$ & Millipore, Chemicon, MAB326R \\
\hline NG2 chondroitin sulfate proteoglycan & mouse anti-NG2 & $1: 500$ & $\begin{array}{l}\text { Millipore, Upstate, } \\
05-710\end{array}$ \\
\hline 5-bromodeoxyurudine (BrdU) & rat anti-BrdU & $1: 500$ & AbD Serotec, OBT0030CX \\
\hline vesicular glutamate transporter 2 (VGLUT2) & guinea pig anti-VGLUT2 & $1: 5000$ & Millipore, Chemicon, AB5907 \\
\hline
\end{tabular}

TAM-induced $\beta$-gal expression in the adult neurogenic regions, i.e. SVZ and dentate gyrus (Additional file 1). In contrast, no $\beta$-gal activity was observed following vehicle injections in the progeny derived from founder 2 . However, in mice derived from founder 1 , numerous $\beta$-gal positive profiles could be detected after vehicle injection indicating unspecific recombination events (data not shown). Therefore, only the transgenic DCXCreERT2 founder 2 line was expanded and employed for the following experiments.

\section{Expression and sub-cellular localization of CreERT2 in DCX positive $(\mathrm{DCX}+)$ cells}

To validate that CreERT2 expression coincides with endogenous DCX expression in the DCX-CreERT2 transgenic mice, we investigated their respective expression patterns. At the cellular level, CreERT2 was detected in virtually all DCX+ cells of the developing CNS (E15.5). Furthermore, one day after injection of TAM, the CreERT2 has been translocated to the nucleus (Figure 1a). Similarly, in the adult brain, CreERT2 expression was, one day after TAM injection, strictly restricted to the nucleus of DCX + cells (Figure 1b). Nuclear localization is induced by TAM administration and is a prerequisite for CreERT2 activity [24].

To determine the time window in which CreERT2 exerts its function in the nucleus after the TAM injection, DCX-CreERT2 adult mice were perfused at different time points post-injection and the sub-cellular localization of the CreERT2 was assessed. Seven days after TAM injection, the nuclear localization was dramatically decreased as compared to the first day. At this time point, CreERT2 expression was still co-localized with DCX, but its distribution returned to be mostly cytoplasmic (Figure 1c). Furthermore, two weeks after TAM injection, CreERT2 was exclusively localized in the cytoplasm (Figure 1d and 1e). Taken together, our results indicate that the CreERT2 nuclear localization rapidly recedes after the last TAM administration, indicating that CreERT2 activity was transient and virtually ceased after 7 days.

\section{Assessment of CreERT2 activity in neuronal precursor cells}

Having confirmed the correct co-localization of CreERT2 with DCX+cells, we then analyzed recombination activity and specificity. To this end, we mated DCX-CreERT2 mice with Rosa26 $6^{\text {lacZ }}$ or CAG-CATEGFP reporter mice, which allow to monitor the activation of the respective reporter gene expression, following successful excision of the loxP-flanked cassette. The fate of DCX-expressing cells can then be followed by analyzing reporter gene expression at various time points following recombination. 

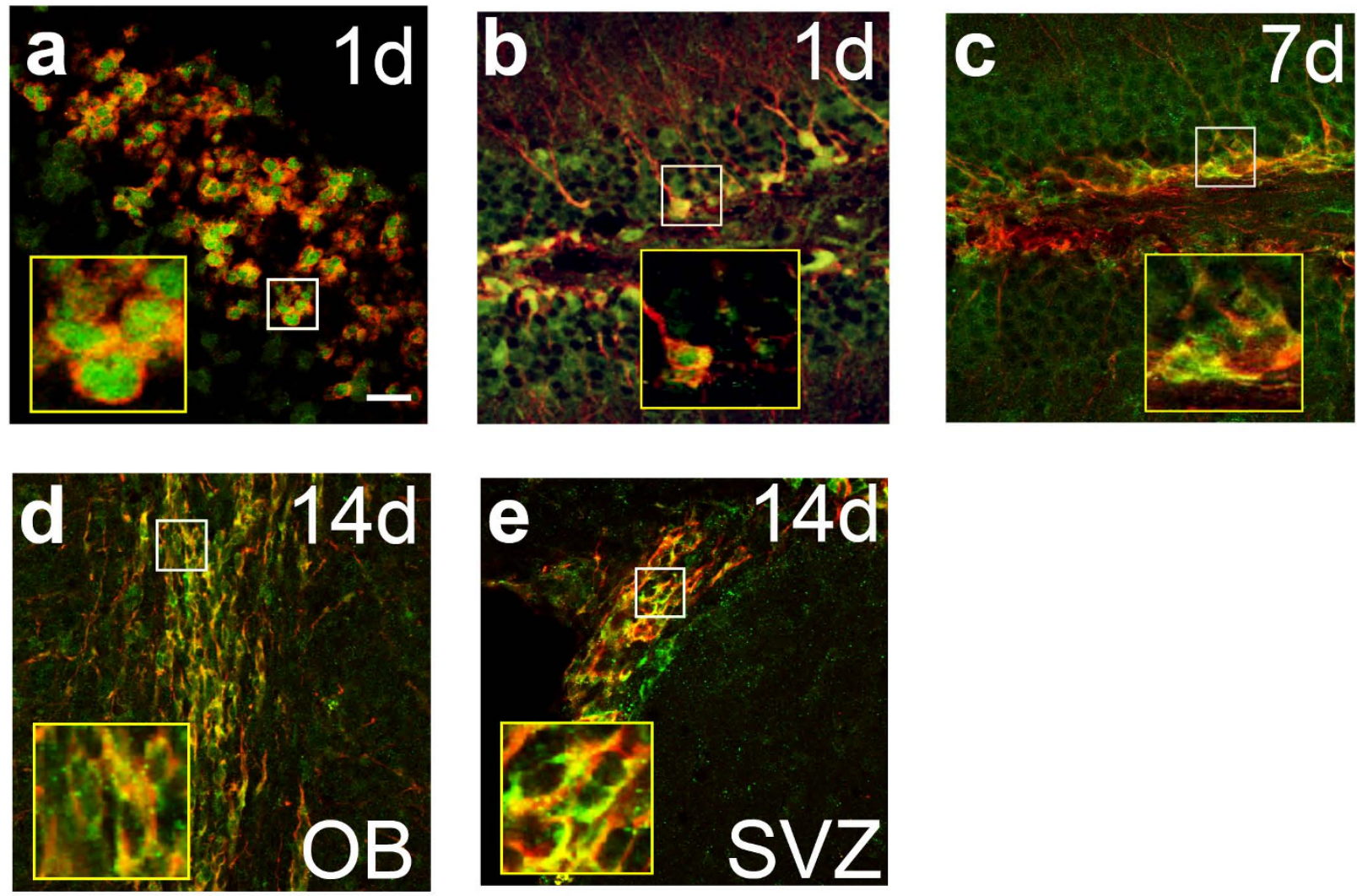

Figure 1 CreERT2 cellular sub-localization in DCX-expressing cells. a) Immunodetection showing subcellular localization of CreERT2 (green) within DCX-expressing cells (red) in the cortex of an E15.5 embryo injected with TAM at E14.5. b to e) Cre subcellular localization detected in the adult DCX-CreERT2 mice injected daily for 5 days with TAM. Immunodetection of CreERT2 (green) in the DG (b) 1 day and (c) 7 days after the last TAM injection in DCX-expressing cells (red). Immunodetection of CreERT2 (green) in the (d) OB and (e) SVZ 14 days after the last TAM injection in DCX-expressing cells (red). Insets show higher magnification of the selected areas. Scale bar in (a) $=33 \mu \mathrm{m}$.

The CreERT2 activity at embryonic stages was analyzed first. Twenty-four hours after a single TAM injection performed on E14.5, X-gal staining revealed that $\beta$-gal expression was restricted to the developing CNS and dorsal root ganglia (DRGs) (Figure 2). This distribution coincided with the pattern of endogenous DCX expression at this stage (Figure 2a). Activation of CreERT2 at E17.5 by a single TAM-injection led to a wide distribution of EGFP reporter expression in the adult brain (Figure $2 \mathrm{~d}$ to $2 \mathrm{k}$ and Additional file 2). EGFP + cells were detected in most regions of the brain parenchyma, such as in the granular cell layer of dentate gyrus, striatum, cortex, thalamus, Ammon's horn (CA1), etc. according to DCX expression pattern at E17.5.

Noteworthy, virtually all EGFP+ cells expressed NeuN, and thus had become mature neurons (Figure $2 \mathrm{~d}$ to $2 \mathrm{~g}$ ). EGFP expression was neither detected in DCX-positive cells in the SVZ (Figure $2 \mathrm{f}$ and $2 \mathrm{~g}$ ), nor in the rostral migrating stream (RMS) (data not shown) and subgranular zone (SGZ) of the dentate gyrus (Figure $2 \mathrm{~d}$ and $2 \mathrm{e}$ ).
A few EGFP+ cells could be found in or in close association to the ependymal layer of the lateral ventricles (Figure 2f, arrows). These EGFP + cells, however, did neither co-express NeuN nor DCX and their nature remains to be elucidated.

Due to the lower numbers of neurons continuously generated in the adult CNS, adult mice were injected with TAM on 5 consecutive days and then perfused for analysis 4 weeks after the last injection. At this time point, SVZ-generated EGFP+ cells reached the OB and were distributed mainly within the granular cell layer $(\mathrm{GrO})$ (Figure $2 \mathrm{~h}$ and $2 \mathrm{i}$ ) and to a lower extent in the periglomerular cell layer (pGl). The EGFP+ cells present in the $\mathrm{OB}$ were found to express the mature neuronal marker NeuN, whereas no co-expression of DCX could be detected (Figure $2 \mathrm{~h}$ and 2i). Within the rostral RMS in contrast, a few scattered EGFP-expressing cells appeared to have retained expression of DCX. Moreover, only rare EGFP+ cells could be found in the SVZ (data not shown). Similarly to cells detected in the OB, 

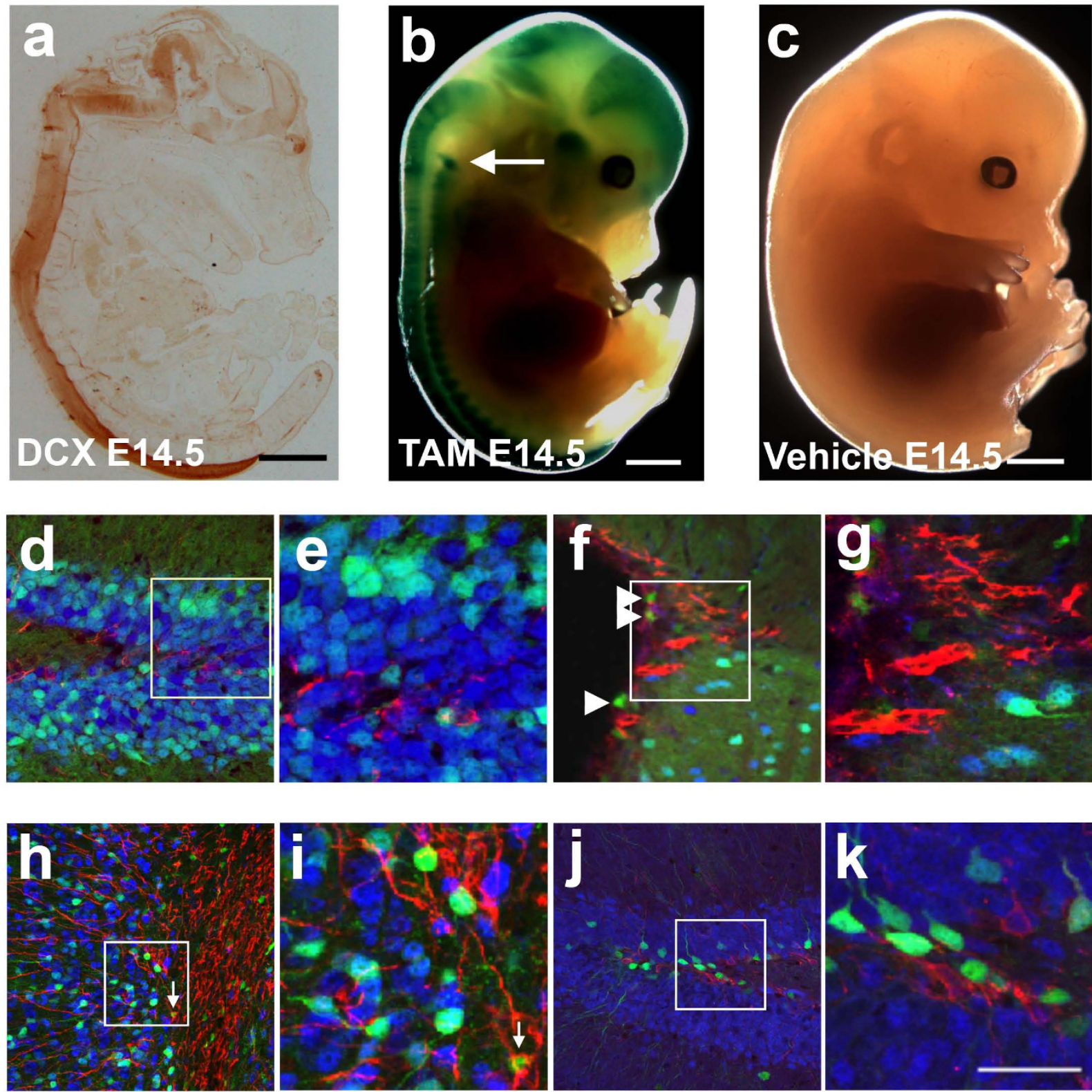

Figure 2 Induction of reporter gene expression by TAM injections at different developmental stages. a) Immunodetection of DCX expression in an E14.5 mouse embryo. Detection of $\beta$-gal activity at E15.5 in a DCX-CreERT2: Rosa26 $6^{\text {lacZ }}$ embryos injected with (b) TAM or (c) vehicle at E14.5. Arrow in (b) points to a labeled dorsal root ganglion. No $\beta$-gal signal could be detected in vehicle-injected embryos. Immunodetection of DCX (red), NeuN (blue) and EGFP (green) in the DG ( $d$ and e) and SVZ ( $\mathrm{f}$ and $\mathrm{g}$ ) of a 2 month-old DCX-CreERT2:CAG-CATEGFP mouse injected with TAM at E17.5. Arrowheads in (f) point to EGFP-expressing cells remaining at the ependymal lining. Immunodetection of DCX (red), NeuN (blue) and EGFP (green) in the adult OB ( $\mathrm{h}$ and i) and DG ( $\mathrm{j}$ and $\mathrm{k}$ ) of DCX-CreERT2:CAG-CAT-EGFP mice 4 weeks after TAM injection in the adulthood. Arrow in (i) points at the co-labeling EGFP with DCX at the anterior end of the RMS. Scale bars $=1.7 \mathrm{~mm}$ in (a), 2 $\mathrm{mm}(\mathrm{b})$ and $(\mathrm{c}), 50 \mu \mathrm{m}(\mathrm{k})$.

four weeks after TAM administration, EGFP+ cells in the dentate gyrus expressed NeuN and were devoid of DCX (Figure 2j and 2k).

The efficiency and the specificity of the recombination event in DCX-expressing cells were evaluated in the adult SVZ and SGZ. The percentage of all DCX+ cells expressing EGFP was defined as the efficiency of recombination, and the percentage of all EGFP+ cells expressing DCX was defined as the specificity. Since levels of accumulated EGFP within cells were relatively low at 


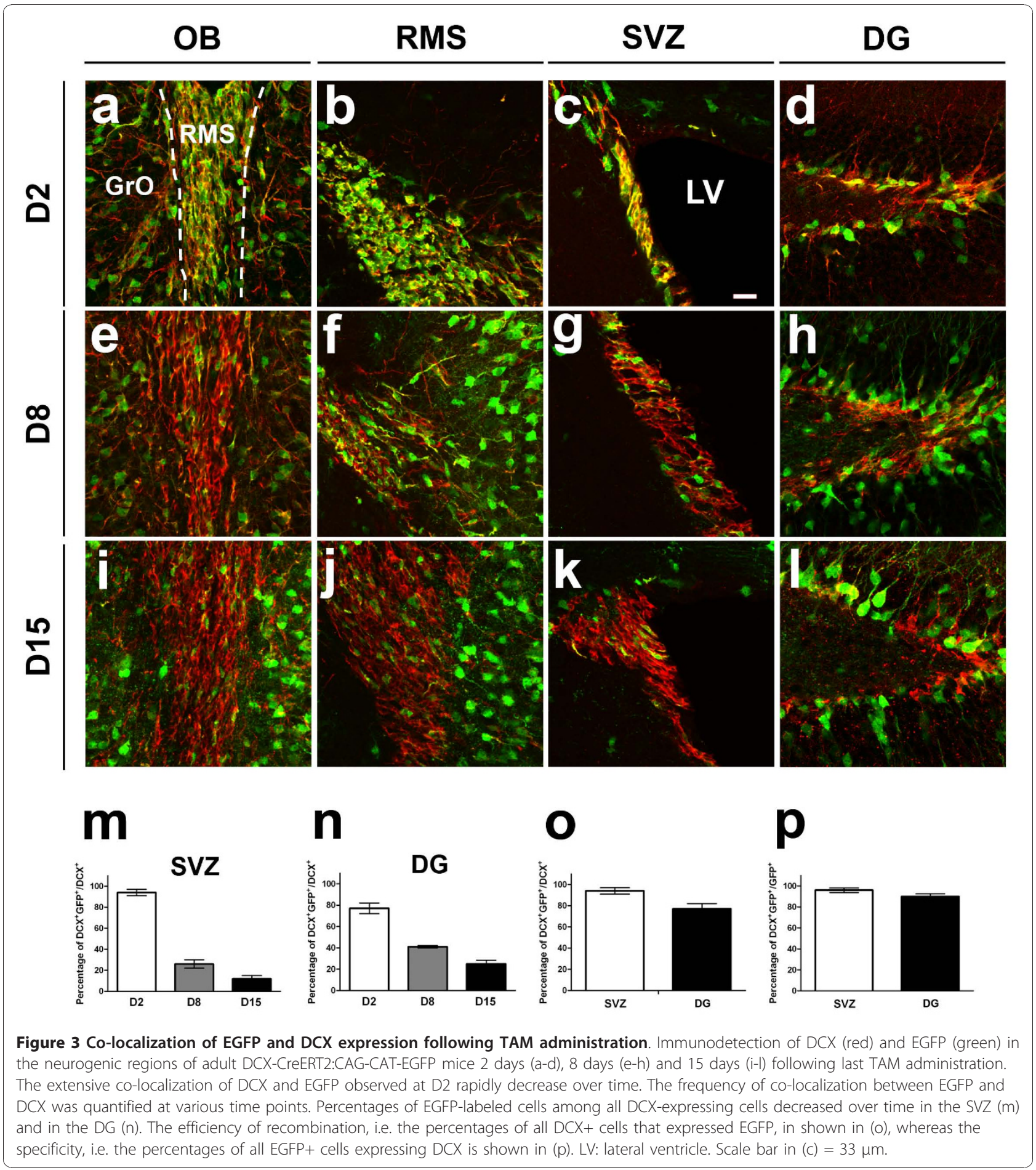

the earliest time point studied, EGFP signals were amplified using an anti-EGFP antibody in all following experiments. In the SVZ, we observed that approximately $94 \%$ DCX+ cells were co-expressing EGFP two days after the last TAM injection (Figure 3c and 3o). At the same time point in the SGZ of the dentate gyrus, EGFP could be detected in approximately $77 \%$ of DCX- expressing cells (Figure 3d and 3o). Moreover, approximately 96\% EGFP+ cells in SVZ and 90\% EGFP+ cells in SGZ (Figure 3p) were co-expressing DCX, demonstrating that the CreERT2 activity was highly efficient and specific.

In order to characterize further the kinetics of the $\mathrm{DCX}+$ cells' emigration from their site of birth to their 
target structures, the distribution of EGFP-expressing cells following recombination was investigated over time. To this end, adult mice were sacrificed eight, fifteen or twenty-nine days after the last TAM injection (D8, D15 and D29, respectively). Co-localization of EGFP expression with DCX and NeuN was analyzed within the SVZ-RMS-OB axis and within the dentate gyrus at these time points.

In contrast to the high percentage of EGFP-expression within DCX+ cells two days after the last TAM injection, the percentage of EGFP-expressing DCX+ neurons in the SGZ decreased to $41 \%$ at D8, and declined gradually to roughly $25 \%$ of all DCX+ cells at D15 (Figure 3). Concomitantly, the frequency of co-localization in the SVZ decreased at D8 to $26.7 \%$, further diminished to $12.5 \%$ at D15 (Figure 3). Finally, at D29, only rare EGFP + cells remained within the SVZ and were found to express DCX, whereas no co-localization could be detected in the SGZ at this time point. Taken together, our data indicate that the main emigration wave of EGFP-labeled neurons departed away from the SVZ within the first 15 days (Figure 3).

\section{Neuronal phenotypes of EGFP+ cells integrated into adult neurogenic regions}

EGFP+ cells migrating along the RMS from D2 to D15 were found to maintain an immature neuronal morphology and only rare co-localization with NeuN could be documented (Figure 4). Over the next 4 weeks, expression of NeuN within EGFP+ cells was broadly induced as cells reached the $\mathrm{GrO}$ or the pGl of the olfactory bulb (Figure $2 \mathrm{~h}$ and 2i, Figure $4 \mathrm{a}$, e and $4 \mathrm{i}$ ). Notably, in the $\mathrm{GrO}$, we found only weak expression of DCX in EGFP + cells. In contrast, DCX was still strongly expressed in the cytoplasm of EGFP+ located at the anterior end of the RMS (Figure 2i, arrow), revealing that the expression of DCX decreased gradually as EGFP+ cells migrated into their target areas (data not shown). These observations reveal that DCX expression in cells migrating to the olfactory bulb is regionally regulated. In a similar fashion, EGFP-expressing cells in the dentate gyrus integrated in the inner granular layer over time and gradually induced the expression of NeuN. Quantitative analyses revealed that 15 days after the last TAM administration, more than $80 \%$ of EGFP+ cells found in the dentate gyrus (Figure $4 \mathrm{~m}$ ) and virtually all EGFP+ cells found in the olfactory bulb (data not shown) expressed the mature neuronal marker NeuN.

To further characterize the neuronal phenotypes of EGFP-labeled neurons, the presence of neurotransmitter-specific markers and calcium-binding proteins was investigated by immunohistology at D29 (Figure 5). In agreement with previous studies $[25,26]$, expression of
GAD65, a marker found in GABAergic neurons, could be detected at this time point in EGFP-expressing cells located in the OB. Moreover, a sub-population of periglomerular EGFP+ cells was found to co-express TH, a marker specific for dopaminergic neurons (Figure 5).

On the other side, VGLUT2, a commonly used marker for glutamatergic terminations, could be detected in the granular layer of the dentate gyrus and surrounded EGFP + cells at D29, revealing that EGFP-expressing cells received glutamatergic inputs (Figure 5). In addition, we scrutinized for the expression of the calcium-binding proteins calbindin-D28K, calretinin and parvalbumin in the EGFP-labeled granule neurons at this time point. The calbindin-D28K, which is expressed in mature granule neurons, could be detected in most EGFP+ cells of the dentate gyrus (Figure 5). In contrast, no parvalbumin and only weak expression of calretinin could be detected in EGFP + cells of the dentate gyrus at this time point, although cells expressing high levels of parvalbumin or calretinin, the latter been specifically found in newly generated granule cells, could be detected in the vicinity (see for example arrow in Figure 5e).

\section{Proliferative capacity of EGFP+ cells in the adult neurogenic regions}

DCX expression takes place in a relatively heterogeneous population of neuronal precursors and young neurons of various maturation stages and proliferative statuses. Administration of BrdU to label proliferative cells was performed at various time points following recombination. At the earliest time point investigated, D2, approximately $51.1 \%$ of EGFP+ cells in the SVZ, but only $7.7 \%$ of EGFP+ cells in the SGZ incorporated BrdU respectively, confirming that a fraction of the cells was still proliferating (Figure 6). The higher proportion of mitotically active cells in the SVZ might be explained by the emigration of post-mitotic young neurons out of the SVZ towards the OB, leaving the most immature cells behind. Furthermore, no more BrdU incorporation in EGFP+ cells was observed in SGZ at D15 (Figure 6), underscoring the temporally limited proliferative capacity of DCX+ cells. In contrast, although no more BrdU incorporation in EGFP+ cells was observed in SGZ at D15, a few BrdU+/EGFP+ co-labeling cells could be found in RMS (data not shown), suggesting that some EGFP+ cells in SVZ/RMS/OB axis could keep proliferative capacity until at least D15.

\section{EGFP+ cells outside of adult neurogenic regions}

Following administration of TAM to adult DCXCreERT2:CAG-CAT-EGFP mice, EGFP+ cells could be detected outside of the described neurogenic regions. In this respect, scattered DCX-expressing cells have previously been reported in adult cerebral cortex of 


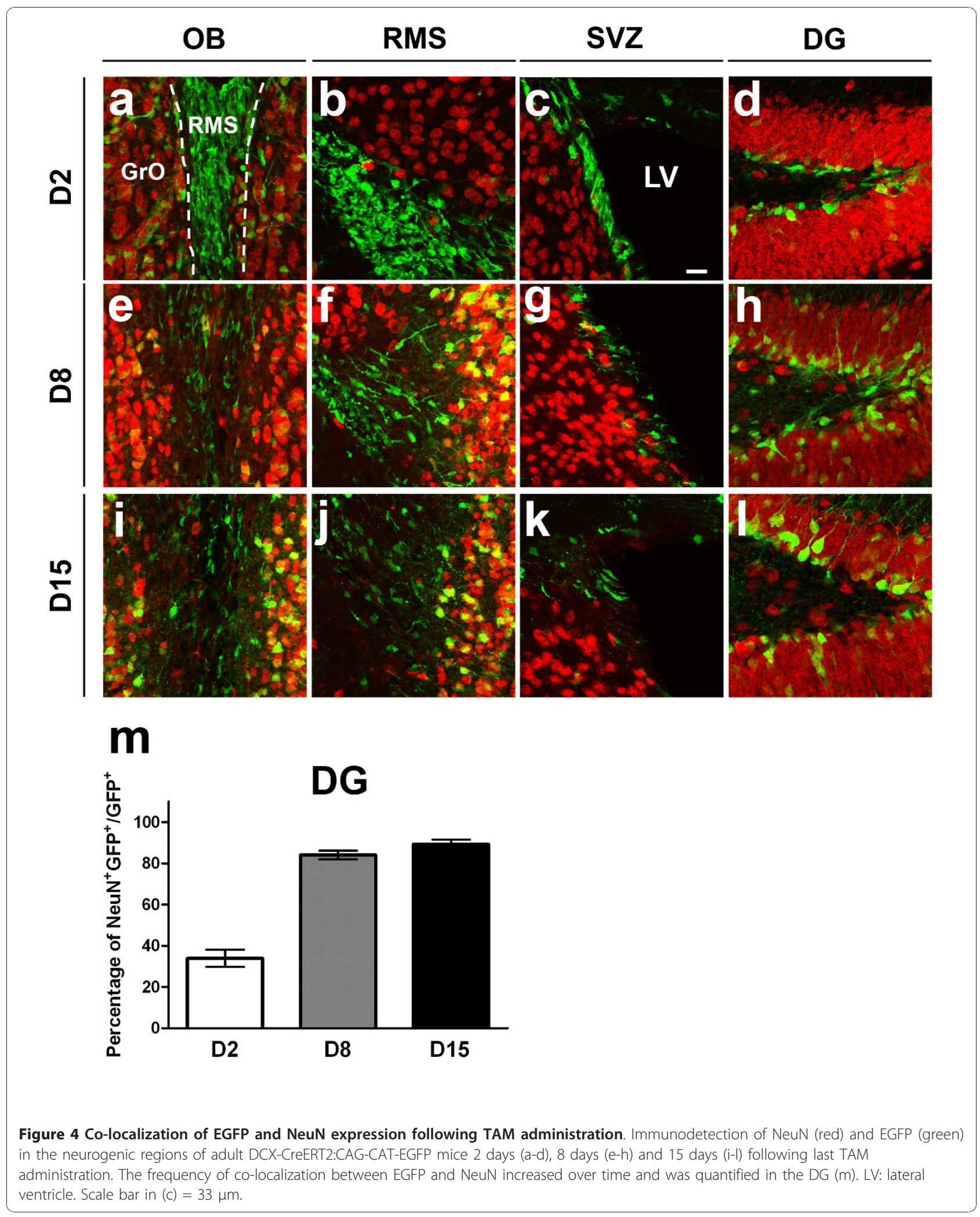



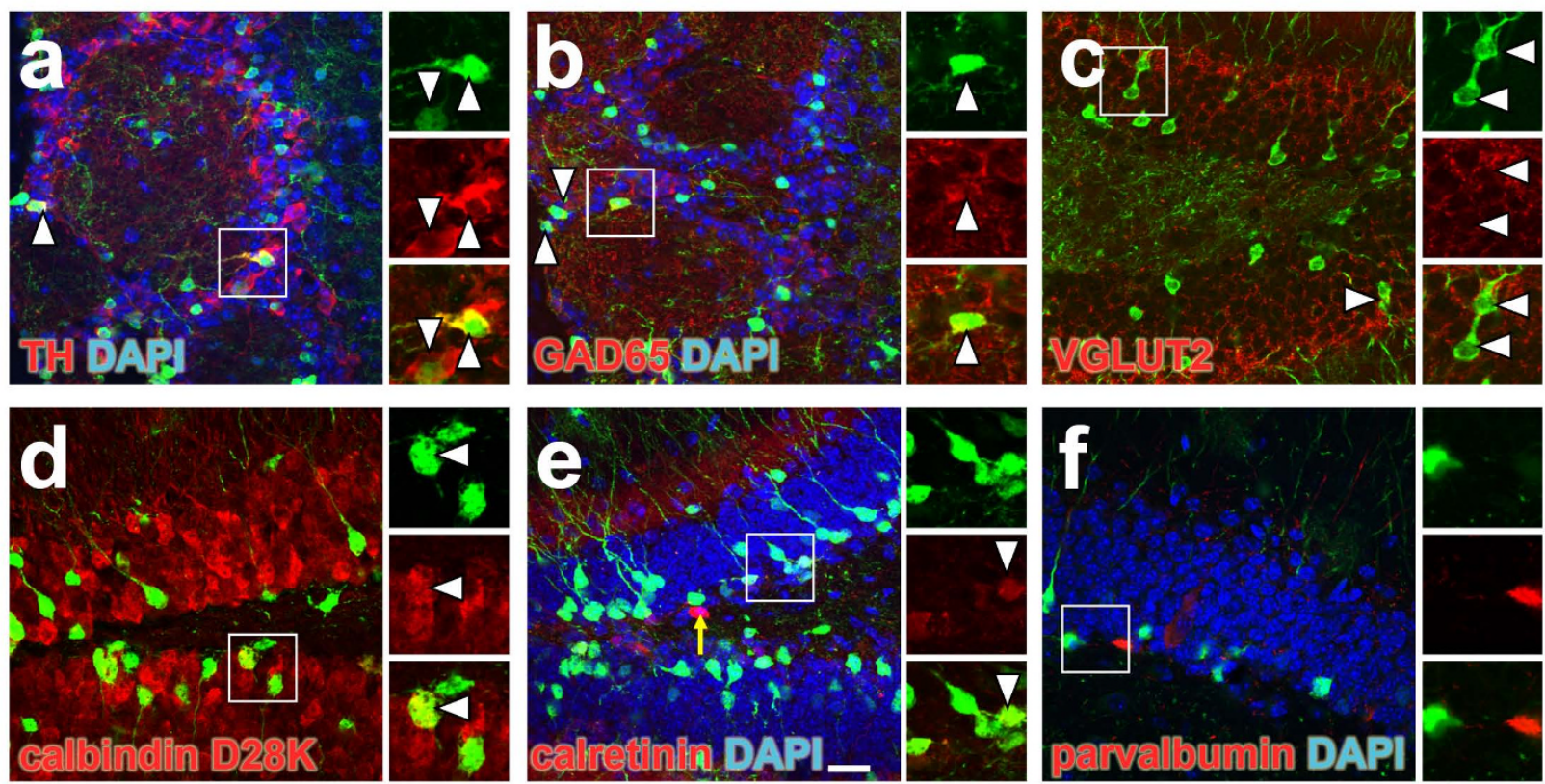

Figure 5 Co-localization of EGFP and neuronal subtype-specific markers. Twenty-nine days after the last TAM administration, the EGFPexpressing cells (green) were examined for the expression of specific markers (red). (a) co-localization with the dopaminergic marker tyrosine hydroxylase (TH) in the pGl, (b) co-localization with the GABAergic marker glutamate decarboxylase 65 (GAD65) in the pGl and (c) co-localization with the glutamatergic marker vesicular glutamate transporter 2 (VGLUT2) in the DG. (d) Co-localization with DG mature granule cell marker calbindin-D28K, (e) co-localization with the early DG granule cell marker calretinin. Arrow points to a cell expressing high levels of calretinin, but no EGFP, (f) absence of co-localization with parvalbumin in the DG. Scale bar in (e) $=33 \mu \mathrm{m}$.

rodents, cats and primates [7,27]. To validate that EGFP expression in cells located outside of the neurogenic regions ensued from concomitant expression of DCX, we scrutinized by immunohistochemistry DCX expression pattern in the whole adult brain in respect to the activation of the EGFP expression.

Low to moderate levels of DCX expression could be detected in cells dispersed throughout the cerebral cortex (Figure 7). Some weak DCX expression could also be perceived in corpus callosum, as well as around the $3^{\text {rd }}$ ventricle and hypothalamus, the molecular cell layer (MCL) and the granular cell layer (GCL) of cerebellum (data not show). Four weeks after TAM injection, EGFP+ cells also appeared in these regions (Figure 7). The reporter expression levels however were significantly higher than the endogenous DCX expression levels, since upon recombination, expression of the reporter gene was under the control of a strong promoter. Importantly, EGFP+ cells located outside of the neurogenic regions were not proliferative, as demonstrated by the absence of BrdU incorporation. Therefore, the nature and fate of these immature neurons remains to be deciphered.

\section{Discussion}

In this report, we demonstrated that CreERT2-mediated recombination can be efficiently and specifically targeted in vivo in DCX-expressing cells, i.e. in the neuronal precursors and young neurons, using a DCX promoter-driven CreERT2. In contrast to DCX promoter-driven reporter lines previously generated $[10,11]$, the DCXCreERT2 construct described here additionally encodes the 3'UTR region of the DCX mRNA. The large DCX 3'UTR is known to contain post-transcriptional regulation elements of gene expression [28]. However, under experimental conditions used in this study, no overt differences in the expression pattern of the CreERT2 transgene could be documented in comparison to former lines devoid of DCX 3'UTR sequences. Nevertheless, the presence of DCX 3'UTR could lead to a more faithful CreERT2 expression pattern within the DCX-expressing cell population and more investigation will be required to understand its function.

One day after TAM administration, the CreERT2 protein was translocated to the nuclear compartment of DCX-expressing cells where it could proceed to recombination. The latter resulted in a rapid activation of reporter expression; $\beta$-gal or EGFP could be readily detected in the embryonic, as well as in the adult CNS, one day after tamoxifen injection (Figure 2). Following five daily tamoxifen administrations, $94 \%$ DCX+ cells in SVZ and 77\% DCX+ cells in the dentate gyrus induced expression of EGFP, demonstrating a high efficiency of 


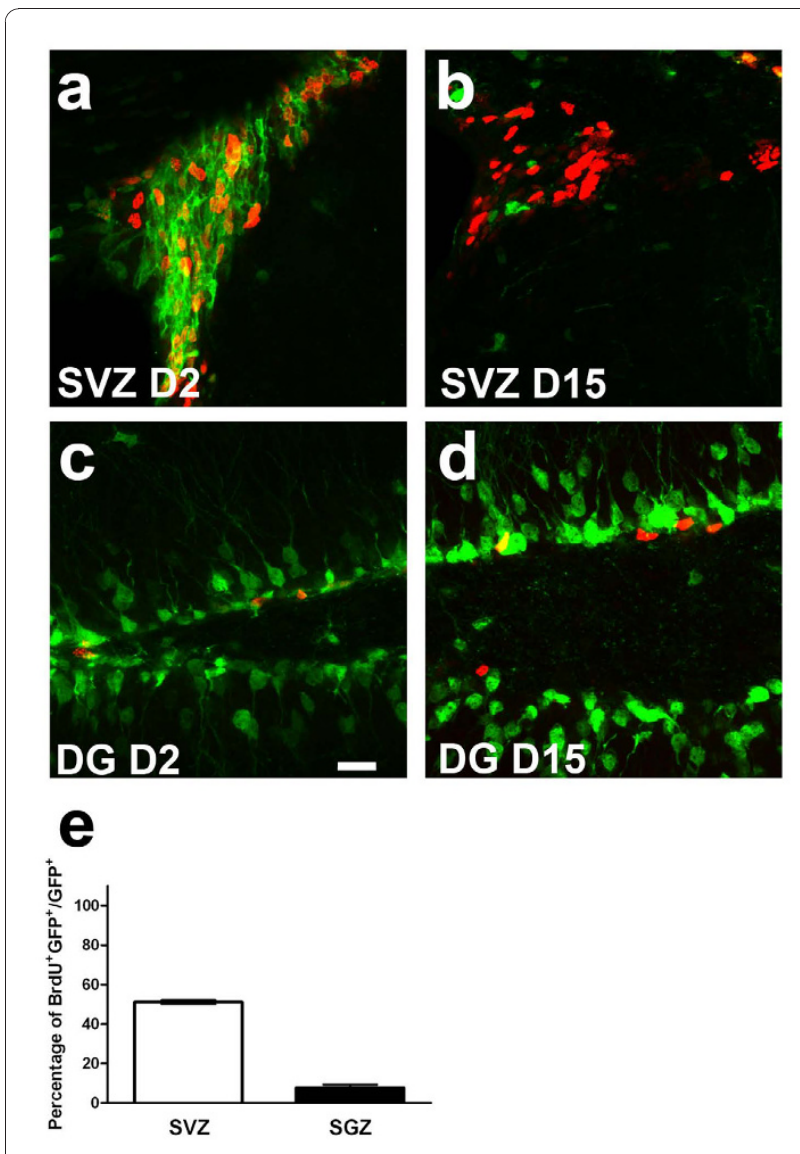

Figure 6 Proliferative potential of EGFP-labeled cells. One day or 14 days after the last TAM injection, dividing cells were labeled via a single BrdU injection and co-localization of EGFP with BrdU was examined at day 2 (a and c) and day 15 (b and d), respectively, in the SVZ and DG. Quantification on day 2 revealed that the percentage of all EGFP+ cells labeled with BrdU rapidly decreases and is shown in (e). Scale bar in (c) $=33 \mu \mathrm{m}$.

recombination using our experimental paradigms. On the other side, about $96 \%$ of EGFP+ cells in SVZ and 90\% of EGFP+ cells in SGZ were co-expressing DCX, confirming that the recombination activity was induced with high specificity. (Figure 3). As the fate of EGFP+ cells was observed to be solely neuronal, we conclude that the absence of DCX expression in a small fraction of the EGFP+ resulted from the maturation-associated downregulation of DCX+ over the 5 days of TAM injection.

Although the nuclear translocation of the CreERT2 was transient, expression of the reporter got permanently induced following recombination, which allows for the long-term analysis of cell types arising from $\mathrm{DCX}+$ cells. Hence, one month after recombination in the DCX-CreERT2, the vast majority of the EGFP+ cells in the neurogenic target regions expressed NeuN, a marker found in mature neurons. In addition, a few
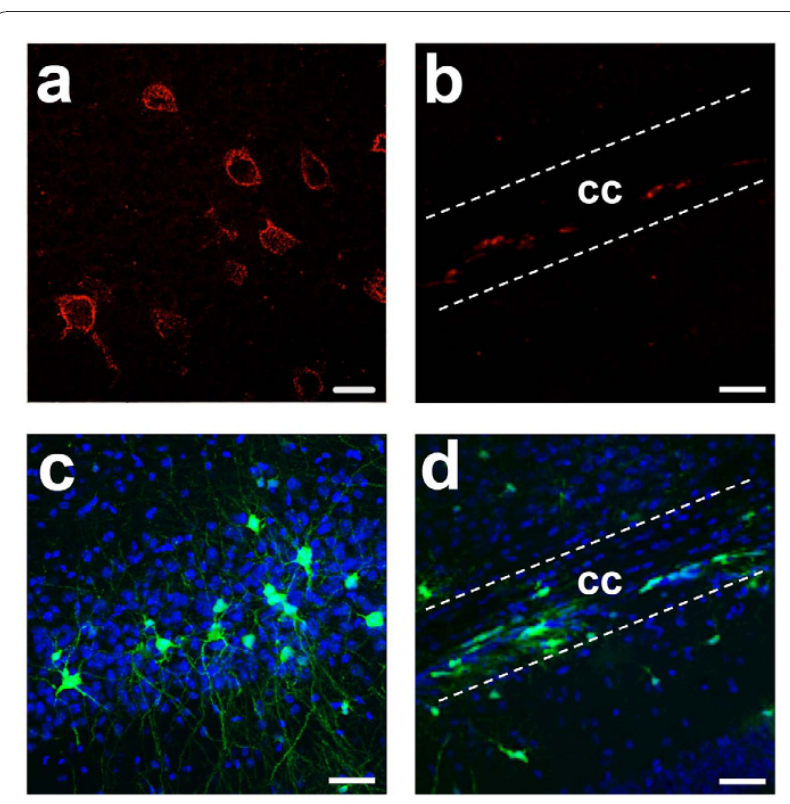

Figure 7 Expression of DCX and EGFP outside of neurogenic areas. Low levels of DCX expression can be detected outside of neurogenic areas. For example, DCX-expressing cells were detected by immunohistochemistry in the piriform cortex (a) and in the corpus callosum (b). Accordingly, EGFP-expressing cells were detected following TAM administration in the piriform cortex (c) and corpus callosum (d). Scale bar in (a) = $33 \mu \mathrm{m}$; Scale bar (b), (c) and $(d)=50 \mu \mathrm{m}$.

EGFP+ cells along the neuroblasts' migratory route or localized outside neurogenic regions were found to express low levels of DCX. Importantly, one month after the last TAM injection, no co-localization between the EGFP signal and the expression of GFAP (astrocyte marker), CNPase (oligodendrocyte marker) or Iba I (microglia marker) was detected (data not shown). This substantiates evidences that DCX-expressing cells are determined to become neurons under physiological conditions. This contrast with the use of the nestin promoter to drive the expression of the CreERT, which resulted in the labeling of the neural stem cell population generating thereafter a continuous flow of new neurons and glia [17].

Calbindin-D28K, calretinin and parvalbumin belong to the superfamily of low molecular weight calcium-binding proteins and are characteristic of different subpopulations of neurons [29]. Hence, in the dentate gyrus, Calbindin-D28K is as marker of mature granule cells while calretinin is transiently expressed in postmitotic newly generated neurons [30,31]. In agreement with the latter, we observed that EGFP+ granular cells in the dentate gyrus were expressing Calbindin-D28K, a few of them expressed low levels of calretinin, and none of them expressed parvalbumin four weeks after recombination (Figure 5). The absence of co-localization 
between EGFP and parvalbumin reinforced evidence that this GABAergic subpopulation is not replenished by a constant addition of new neurons in adult dentate gyrus, although this matter is still under debate [32-34].

\section{The EGFP+ cells outside the classical adult neurogenic regions}

Following recombination in DCX-CreERT mice, EGFP+ cells were also found within non-neurogenic brain areas. In mammals, DCX+ cells have been reported outside neurogenic regions, including temporal and prefrontal cortex layer II, piriform cortex layer III/endopiriform nucleus, corpus callosum, nucleus accumbens, ventromedial striatum, ventrolateral septum, bed nucleus of the stria terminalis, molecular cell layer, granular cell layer and white matter of cerebellum. The distribution and frequency of these DCX+ cells appear to increase in superior species of the phylogeny, although it remains to be elucidated to which extent this is due to an increase of DCX expression levels and thereby a better immunohistochemical detectability [7,8,35-37].

Intriguingly, the numbers of EGFP+ cells around the $3^{\text {rd }}$ ventricle and hypothalamus appeared markedly higher than the numbers of DCX + cells detected in these regions. The reason of this discrepancy may be related to a very low expression level of DCX in these cells, which would be hardly detectable using current antibodies. In contrast, once DCX-associated recombination occurred, the expression of reporter genes is controlled by a strong constitutive promoter allowing for an easy detection of targeted cells.

The origin and function of DCX-expressing cells outside of the neurogenic regions remain to be elucidated. For instance, it was reported that the neural stem cells can be isolated from virtually every region of the adult CNS [38]. In addition, upon specific treatment, neurogenic events have been induced within the adult cortex, striatum, CA1 region of the hippocampus, and even within the white matter [39-42]. It is tempting to conclude that some of the DCX-expressing cells detected in these regions were generated by a very low rate continuous neurogenesis. However, the absence of BrdU labeling obtained in these cells under physiological conditions suggests that such a mechanism of DCX+ cells generation would be marginal in the best case.

On the other side, there exists good evidence that the extra-neurogenic DCX-expressing cells might have been generated during developmental neurogenesis, but never fully completed their maturation process [43]. These cells would remain in the parenchyma as "quiescent" local neuronal precursors. The existence of such quiescent precursors has also been suggested following grafting experiments in which neural stem cells were injected into the ventricles during cortical development
[44]. Detection of these cells at a later time point revealed that stem cells were integrated as neurons into various brain regions, but at the same time, a certain amount of cells remained as immature neurons in the parenchyma, potentially as a reservoir of precursor cells available for plasticity or local repair.

Recently, another mouse model expressing the DCXCreERT has been reported [34]. In contrast to our model based on the human DCX promoter, Cheng and colleagues used a BAC construct encoding the murine DCX promoter. The latter, together with a possible positional effect of the transgene may explain the differences observed between the two models. For instance, in contrast to our mouse model, the model from Cheng et al. is exclusively active in DCX-expressing cells within the hippocampus [34]. Also, the authors claim that recombination in their DCX-CreERT mice takes only place in post-mitotic neuronal precursors. Given the fact that a significant fraction of all DCX-expressing cells are still in a proliferative state (see Figure 6 and [10]), this suggests that the induction of the DCXCreERT transgene expression reported by Cheng is delayed in respect to the endogenous DCX. Thus, the DCX-CreERT mouse model presented by Cheng and colleagues appears to be well-suited for the study addressing the maturation and fate of newly generated granule cells of the dentate gyrus. Still, there is a lack of model(s) addressing the fate of DCX-expressing cells located outside of the dentate gyrus - such as in the subventricular zone (SVZ) - which is now possible by the model presented in this manuscript.

\section{Conclusion}

We report here a transgenic mouse model based on an inducible Cre recombinase driven by the DCX promoter (DCX-CreERT2). Taken the high specificity and efficiency of recombination in neuroblasts and young neurons, this transgenic mouse model constitutes a powerful tool for tracing neurogenesis and fate-analysis of newly generated neurons. It is moreover a valuable model for studying molecular mechanisms of neural plasticity and neurogenesis through induction or silencing of specific genes in neuroblasts and young neurons. Finally, the possibility to analyze the long-term fate of newly generated neurons will be an asset in the development of innovative therapies against neurologic diseases.

\section{Additional material}

Additional file 1: The DCX-CreERT2 construct and the generation of DCX-CreERT2 transgenic mouse. (a) Schematic representation of the DCX-CreERT2 construct. The 7.7-kb fragment DNA of Dcx-3'-UTR was cloned by RT-PCR and inserted downstream of the CreERT2. The founders were genotyped by (b) PCR and (c) Southern blot (nontransgenic control DNA in lane " $C^{\prime \prime}$ ). Two weeks after TAM injection, 
brains of adult mice originating from founder-derived lines mated with Rosa26 lacz mouse (DCX-CreERT2:Rosa26) were further analyzed by X-gal staining. (d) $\beta$-gal positive cells in the DG of an adult DCX-CreERT2: Rosa26 mouse two weeks after TAM injection. (e) Absence of $\beta$-gal activity in the DG of a DCX-CreERT2:Rosa26 mouse injected two weeks before with the vehicle only (corn oil). Insets show higher magnification of the selected region. E, EcoR V; K, Kpn I. Scale bar in (e) $=50 \mu \mathrm{m}$.

Additional file 2: EGFP expression in the adult brain of DCXCreERT2:CAG-CAT-EGFP mice injected once with TAM at E17.5 Numerous EGFP-expressing cells could be detected, for example, (a) in the GrO, (b) layer II and VI of cerebral cortex, (c) striatum, (d) hippocampal pyramidal layer CA1 (e) and Purkinje cell of cerebellum. gl, glomerular cell layer; Mi, mitral cell layer of olfactory bulb; GrO, granular cell layer of olfactory bulb; Py, pyramidal cell layer of the hippocampus; Rad, stratum radiatum of the hippocampus; MCL, molecular cell layer of cerebellum; GCL, granular cell layer of cerebellum. Scale bar in (e) $=50$ $\mu \mathrm{m}$.

\section{Acknowledgements}

This work was funded by the Initiative and Networking Fund in the framework of the Helmholtz Alliance of Systems Biology and of Mental Health in an Ageing Society "HelMA"(HA-215), Bayerischer Forschungsverbund ForNeuroCell (F2-F2410-10c/20697), the "European Mouse Mutagenesis Program (EUCOMM)" (LSHM-CT-2005-018931), EU-FP6project "DiMI", LSHB-CT-2005-512146, the German Federal Ministry of Education and Research (BMBF 01GG0706) and Hoffmann La Roche, Basel.

\section{Author details}

'Institute of Developmental Genetics, Helmholtz Zentrum Muenchen, German Research Center for Environmental Health $(\mathrm{GmbH})$, Ingolstaedter Landstrasse 1, D-85764 Neuherberg, Germany. ${ }^{2}$ Max Planck Institute of Psychiatry, Kraepelinstrasse 2-10, D-80804 Munich, Germany. ${ }^{3}$ Institute of Molecular Regenerative Medicine, Paracelsus Medical University Salzburg, Strubergasse 21, 5020 Salzburg, Austria. ${ }^{4} \mathrm{TUM}$, Technical University Munich, Chair of Developmental Genetics, c/o Ingolstaedter Landstrasse 1, D-85764 Neuherberg, Germany. ${ }^{5} \mathrm{DZNE}$, Deutsches Zentrum für Neurodegenerative Erkrankungen, Ludwig Maximilian University, c/o Adolf Butenandt-Institut für Biochemie, Schillerstraße 44, 80336 Munich, Germany.

\section{Authors' contributions}

JZ: the main author, participated in the design of the study, performed all associated mouse breeding and histological work, did most of the molecular work and all histological analysis and drafted the manuscript. FG: Performed some essential clonings and interpreted together with JZ the molecular work. KK: assisted in the analysis of the histological sections. DMWW (responsible for the project coordination), LA, WW and SCD were initiating and designing the study; reviewed (DMVW, LA, WW) and wrote the manuscript (SCD). All authors contributed to the project with continuous updates on the research topic and influenced thereby the progress of the project. All authors have reviewed and contributed to the different draft versions of the manuscript. All have read and approved the final manuscript.

Received: 9 September 2010 Accepted: 31 December 2010 Published: 31 December 2010

\section{References}

1. van Praag H, Schinder AF, Christie BR, Toni N, Palmer TD, Gage FH: Functional neurogenesis in the adult hippocampus. Nature 2002, 415(6875):1030-1034.

2. Ramirez-Amaya V, Marrone DF, Gage FH, Worley PF, Barnes CA: Integration of new neurons into functional neural networks. J Neurosci 2006, 26(47):12237-12241.

3. Carleton A, Petreanu LT, Lansford R, Alvarez-Buylla A, Lledo PM: Becoming a new neuron in the adult olfactory bulb. Nat Neurosci 2003, 6(5):507-518.

4. Brown JP, Couillard-Despres S, Cooper-Kuhn CM, Winkler J, Aigner L, Kuhn HG: Transient expression of doublecortin during adult neurogenesis. J Comp Neurol 2003, 467(1):1-10.
5. Couillard-Despres S, Winner B, Schaubeck S, Aigner R, Vroemen M, Weidner N, Bogdahn U, Winkler J, Kuhn HG, Aigner L: Doublecortin expression levels in adult brain reflect neurogenesis. Eur J Neurosci 2005, 21(1):1-14.

6. Francis F, Koulakoff A, Boucher D, Chafey P, Schaar B, Vinet MC, Friocourt $G$, McDonnell N, Reiner O, Kahn A, et al: Doublecortin is a developmentally regulated, microtubule-associated protein expressed in migrating and differentiating neurons. Neuron 1999, 23(2):247-256.

7. Nacher J, Crespo C, McEwen BS: Doublecortin expression in the adult rat telencephalon. Eur J Neurosci 2001, 14(4):629-644.

8. Yang HK, Sundholm-Peters NL, Goings GE, Walker AS, Hyland K, Szele FG: Distribution of doublecortin expressing cells near the lateral ventricles in the adult mouse brain. J Neurosci Res 2004, 76(3):282-295.

9. Karl C, Couillard-Despres S, Prang P, Munding M, Kilb W, Brigadski T, Plotz S, Mages W, Luhmann H, Winkler J, et al: Neuronal precursor-specific activity of a human doublecortin regulatory sequence. I Neurochem 2005, 92(2):264-282.

10. Couillard-Despres S, Winner B, Karl C, Lindemann G, Schmid P, Aigner R, Laemke J, Bogdahn U, Winkler J, Bischofberger J, et al: Targeted transgene expression in neuronal precursors: watching young neurons in the old brain. Eur J Neurosci 2006, 24(6):1535-1545.

11. Couillard-Despres $S$, Finkl R, Winner B, Ploetz S, Wiedermann D, Aigner R, Bogdahn U, Winkler J, Hoehn M, Aigner L: In vivo optical imaging of neurogenesis: watching new neurons in the intact brain. Mol Imaging 2008, 7(1):28-34.

12. Ladewig J, Koch P, Endl E, Meiners B, Opitz T, Couillard-Despres S, Aigner L, Brustle $\mathrm{O}$ : Lineage selection of functional and cryopreservable human embryonic stem cell-derived neurons. Stem Cells 2008, 26(7):1705-1712

13. Couillard-Despres S, Quehl E, Altendorfer K, Karl C, Ploetz S, Bogdahn U, Winkler J, Aigner $L$ : Human in vitro reporter model of neuronal development and early differentiation processes. BMC Neurosci 2008, 9:31.

14. Maekawa M, Takashima N, Matsumata M, Ikegami S, Kontani M, Hara Y, Kawashima H, Owada Y, Kiso Y, Yoshikawa T, et al: Arachidonic acid drives postnatal neurogenesis and elicits a beneficial effect on prepulse inhibition, a biological trait of psychiatric illnesses. PLoS One 2009, 4(4): e5085.

15. Mao Y, Ge X, Frank CL, Madison JM, Koehler AN, Doud MK, Tassa C, Berry EM, Soda T, Singh KK, et al: Disrupted in schizophrenia 1 regulates neuronal progenitor proliferation via modulation of GSK3beta/betacatenin signaling. Cell 2009, 136(6):1017-1031.

16. David DJ, Samuels BA, Rainer Q, Wang JW, Marsteller D, Mendez I, Drew M, Craig DA, Guiard BP, Guilloux JP, et al: Neurogenesis-dependent and -independent effects of fluoxetine in an animal model of anxiety/ depression. Neuron 2009, 62(4):479-493.

17. Lagace DC, Whitman MC, Noonan MA, Ables JL, DeCarolis NA, Arguello AA, Donovan MH, Fischer SJ, Farnbauch LA, Beech RD, et al: Dynamic contribution of nestin-expressing stem cells to adult neurogenesis. $J$ Neurosci 2007, 27(46):12623-12629.

18. Chen J, Kwon CH, Lin L, Li Y, Parada LF: Inducible site-specific recombination in neural stem/progenitor cells. Genesis 2009, 47(2):122-131.

19. Imayoshi I, Ohtsuka T, Metzger D, Chambon P, Kageyama R: Temporal regulation of Cre recombinase activity in neural stem cells. Genesis 2006, 44(5):233-238.

20. Mori T, Tanaka K, Buffo A, Wurst W, Kuhn R, Gotz M: Inducible gene deletion in astroglia and radial glia-a valuable tool for functional and lineage analysis. Glia 2006, 54(1):21-34.

21. Doerflinger NH, Macklin WB, Popko B: Inducible site-specific recombination in myelinating cells. Genesis 2003, 35(1):63-72.

22. Kawamoto S, Niwa H, Tashiro F, Sano S, Kondoh G, Takeda J, Tabayashi K, Miyazaki J: A novel reporter mouse strain that expresses enhanced green fluorescent protein upon Cre-mediated recombination. FEBS Lett 2000, 470(3):263-268.

23. Soriano P: Generalized lacZ expression with the ROSA26 Cre reporter strain. Nat Genet 1999, 21(1):70-71.

24. Leone DP, Genoud S, Atanasoski S, Grausenburger R, Berger P, Metzger D, Macklin WB, Chambon P, Suter U: Tamoxifen-inducible glia-specific Cre mice for somatic mutagenesis in oligodendrocytes and Schwann cells. Mol Cell Neurosci 2003, 22(4):430-440. 
25. Hack MA, Saghatelyan A, de Chevigny A, Pfeifer A, Ashery-Padan R, Lledo PM, Gotz M: Neuronal fate determinants of adult olfactory bulb neurogenesis. Nat Neurosci 2005, 8(7):865-872.

26. Winner B, Cooper-Kuhn CM, Aigner R, Winkler J, Kuhn HG: Long-term survival and cell death of newly generated neurons in the adult rat olfactory bulb. Eur J Neurosci 2002, 16(9):1681-1689.

27. Cai Y, Xiong K, Chu Y, Luo DW, Luo XG, Yuan XY, Struble RG, Clough RW, Spencer DD, Williamson A, et al: Doublecortin expression in adult cat and primate cerebral cortex relates to immature neurons that develop into GABAergic subgroups. Exp Neurol 2009, 216(2):342-356.

28. Horisawa K, Imai T, Okano H, Yanagawa H: 3'-Untranslated region of doublecortin mRNA is a binding target of the Musashi1 RNA-binding protein. FEBS Lett 2009, 583(14):2429-2434.

29. Eyles DW, McGrath JJ, Reynolds GP: Neuronal calcium-binding proteins and schizophrenia. Schizophr Res 2002, 57(1):27-34.

30. Zhao C, Deng W, Gage FH: Mechanisms and functional implications of adult neurogenesis. Cell 2008, 132(4):645-660.

31. Brandt MD, Jessberger S, Steiner B, Kronenberg G, Reuter K, Bick-Sander A, von der Behrens W, Kempermann G: Transient calretinin expression defines early postmitotic step of neuronal differentiation in adult hippocampal neurogenesis of mice. Mol Cell Neurosci 2003, 24(3):603-613.

32. Liu S, Wang J, Zhu D, Fu Y, Lukowiak K, Lu YM: Generation of functional inhibitory neurons in the adult rat hippocampus. J Neurosci 2003, 23(3):732-736.

33. Keilhoff $G$, Bernstein $H G$, Becker A, Grecksch G, Wolf G: Increased neurogenesis in a rat ketamine model of schizophrenia. Biol Psychiatry 2004, 56(5):317-322.

34. Cheng X, Li Y, Huang Y, Feng X, Feng G, Xiong ZQ: Pulse labeling and long-term tracing of newborn neurons in the adult subgranular zone. Cell Res 2010.

35. Gomez-Climent MA, Guirado R, Varea E, Nacher J: "Arrested development", Immature, but not recently generated, neurons in the adult brain. Arch Ital Biol 2010, 148(2):159-172.

36. Xiong K, Luo DW, Patrylo PR, Luo XG, Struble RG, Clough RW, Yan XX: Doublecortin-expressing cells are present in layer II across the adult guinea pig cerebral cortex: partial colocalization with mature interneuron markers. Exp Neurol 2008, 211(1):271-282.

37. Takacs J, Zaninetti R, Vig J, Vastagh C, Hamori J: Postnatal expression of Doublecortin (Dcx) in the developing cerebellar cortex of mouse. Acta Biol Hung 2008, 59(2):147-161.

38. Palmer TD, Ray J, Gage FH: FGF-2-responsive neuronal progenitors reside in proliferative and quiescent regions of the adult rodent brain. Mol Cell Neurosci 1995, 6(5):474-486.

39. Magavi SS, Leavitt BR, Macklis JD: Induction of neurogenesis in the neocortex of adult mice. Nature 2000, 405(6789):951-955.

40. Takemura NU: Evidence for neurogenesis within the white matter beneath the temporal neocortex of the adult rat brain. Neuroscience 2005, 134(1):121-132.

41. Nakatomi H, Kuriu T, Okabe S, Yamamoto S, Hatano O, Kawahara N, Tamura A, Kirino T, Nakafuku M: Regeneration of hippocampal pyramidal neurons after ischemic brain injury by recruitment of endogenous neural progenitors. Cell 2002, 110(4):429-441.

42. Parent JM, Vexler ZS, Gong C, Derugin N, Ferriero DM: Rat forebrain neurogenesis and striatal neuron replacement after focal stroke. Ann Neurol 2002, 52(6):802-813.

43. Gomez-Climent MA, Castillo-Gomez E, Varea E, Guirado R, Blasco-Ibanez JM, Crespo C, Martinez-Guijarro FJ, Nacher J: A population of prenatally generated cells in the rat paleocortex maintains an immature neuronal phenotype into adulthood. Cereb Cortex 2008, 18(10):2229-2240.

44. Ourednik V, Ourednik J, Flax JD, Zawada WM, Hutt C, Yang C, Park KI, Kim SU, Sidman RL, Freed CR, et al: Segregation of human neural stem cells in the developing primate forebrain. Science 2001, 293(5536):1820-1824.

doi:10.1186/1471-2202-11-158

Cite this article as: Zhang et al.: A powerful transgenic tool for fate mapping and functional analysis of newly generated neurons. BMC Neuroscience 2010 11:158.

\section{Submit your next manuscript to BioMed Central and take full advantage of:}

- Convenient online submission

- Thorough peer review

- No space constraints or color figure charges

- Immediate publication on acceptance

- Inclusion in PubMed, CAS, Scopus and Google Scholar

- Research which is freely available for redistribution

Submit your manuscript at www.biomedcentral.com/submit
C Biomed Central 